\title{
Condições lógico-históricas do conhecimento e formação: contribuições da epistemologia dialética
}

\author{
Simone Alexandre Martins Corbiniano*
}

Resumo: Uma das questões fundamentais da epistemologia dialética é o reconhecimento do caráter histórico da atividade objetiva humana, tanto quanto, de sua elaboração lógica. A historicidade remete à premissa de que a realidade, enquanto objeto a ser conhecido, é atividade humana sensivel, é práxis mediada pelo trabalho. Nesse sentido, a capacidade lógica do pensamento mantém correspondência indispensável com a categoria histórica, que consiste na realidade objetiva do homem e suas condições materiais de existência. As possibilidades da categoria lógica ocorrem no campo em que o pensamento apanha o desenvolvimento histórico, ultrapassando o senso comum, e se subtraindo às especulações abstratas. $\mathrm{Na}$ sociedade capitalista, sobretudo a partir da racionalidade taylorista e fordista, distancia-se a formação do pensamento crítico, político e autônomo, fragilizando as condições lógicas ou teóricas da formação. Trata-se o trabalho de um prelúdio às condições de elaboração da realidade histórica e do pensamento, apesar da racionalização a que o capitalismo a submete.

Palavras-chave: Historicidade. Pensamento. Práxis. Capitalismo. Formação.

\section{Logical-historical conditions of knowledge and formation: the contributions of dialectical epistemology}

\begin{abstract}
One of the fundamental questions underlying dialectical epistemology is the recognition of the historical character of objective human activity and its logical development. Historicity points to the premise that reality, as an object to be known, is sensitive human activity; it is praxis mediated through

* Doutora em Educação pela Universidade Federal de Goiás (UFG). Professora Adjunta do Programa de Pós-graduação em Educação da UFG.E-mail: simone@ antaresbr.com
\end{abstract}


work. In this sense, the logical capacity of thought maintains an indispensable correspondence with the historical category, which is people's objective reality and their material conditions of existence. The possibilities of the logical category occur in the field where thought meets historical development, stretching beyond common sense, and escaping abstract speculations. In capitalist society, especially from the Taylor and Ford rationality onwards, formation has distanced itself from critical, political and autonomous thought, thereby weakening the logical or theoretical conditions of formation. This study is a prelude to the drafting conditions of historical reality and thought, despite the rationalization to which it is submitted by capitalism.

Keywords: Historicity. Thought. Practice. Capitalism. Formation.

\section{Conditions logico-historiques de la connaissance et de la formation: contributions de l'épistémologie dialectique}

Résumé: Une des questions fondamentales de l'épistémologie dialectique est celle de la reconnaissance du caractére historique de l'activité objective humaine et de son élaboration logique. L'historicité renvoie à l'hypothése selon laquelle la réalité en tant qu'objet à être connu est activité humaine sensible, est praxis par l'intermédiaire du travail. Dans ce sens, la capacité logique de la pensée correpond nécessairement à la catégorie historique, qui consiste en la réalité objective de l'homme et de ses conditions matérielles d'existence. Les possibilités de la catégorie logique se produisent dans le domaine dans lequel la pensée saisit le développement historique, dépassant le sens commun et se soustrayant aux spéculations abstraites. Dans la société capitaliste, surtout à partir de la rationalité tayloriste et fordiste, la formation s'éloigne de la pensée critique, politique et autonome, et fragilise par cela les conditions logiques ou théoriques de formation. Ce travail est un prélude aux conditions d'élaboration de la réalité historique et de la pensée, malgré la rationalisation à laquelle les soumet le capitalisme.

Mots-clés: Historicité. Pensée. Praxis. Capitalisme. Formation. 
Para a filosofia da práxis o ser não pode ser separado do pensar, o homem da natureza, a atividade da matéria, o sujeito do objeto; se se faz esta separação, cai-se numa das muitas formas de religião ou na abstração sem sentido.

Antonio Gramsci

\section{Historicidade, elaboração da consciência e atividade lógica do homem}

Segundo a premissa primeira de Marx e Engels em A ideologia alemã, "toda a história humana é, naturalmente, a existência de indivíduos humanos vivos" (MARX; ENGELS, 1984, p. 14), segue-se então a pergunta: o que torna o homem um Ser racional que exprime certo modo de vida? Os autores afirmam:

podemos distinguir os homens dos animais pela consciência, pela religião, por tudo o que se quiser. Mas eles começam a distinguir-se dos animais assim que começam a produzir os seus meios de vida, passo este que é condicionado pela sua organização física. Ao produzirem os seus meios de vida, os homens produzem indiretamente a sua própria vida material. (...) Aquilo que eles são, coincide, portanto, com a sua produção, com o que produzem e também o como produzem (MARX; ENGELS, 1984, p. 15).

A história do homem começa para Marx e Engels (1984), a partir do momento em que ele exerce sua vontade sobre a natureza, por meio do trabalho. Nessa relação com o trabalho, o sujeito se objetiva e constrói historicamente sua humanidade, este fato se reproduz a cada momento, embora o homem aporte sempre em uma realidade já constituída por outros homens (MARX; ENGELS, 1984), pois a consciência se exterioriza no nível das outras consciências. Pode-se compreender ainda que a realidade, como objeto a ser compreendido, é atividade humana sensível, é práxis mediada pelo trabalho. Nesse sentido, a categoria lógica, enquanto elaboração pensada da realidade, mantém correspondência indispensável com a própria realidade 
histórica, que é a atividade objetiva do homem e suas condições materiais de existência.

Para afirmar suas teses, Marx e Engels (1984) opõem-se, especialmente, ao pensamento de Feuerbach, cujo pretenso materialismo alega ser o homem um objeto sensível, mas, em verdade, não o concebe como atividade sensível, pois chega aos enunciados se distanciando da apreensão do homem em sua conexão social concreta. Feuerbach permanece na abstração segundo o entendimento de Marx e Engels (1984), visto que ele não garante a compreensão da construção social com base na atividade sensível viva dos homens, mediada pelo trabalho.

De acordo com Marx e Engels (1984), ao desenvolver a sua produção e o seu intercâmbio material, o homem transforma a sua realidade e muda, no mesmo ato, o seu pensamento. Invertendo o idealismo hegeliano, os autores reforçam que "não é a consciência que determina a vida é a vida que determina a consciência" (MARX; ENGELS, 1984, p. 23), à vista disso, o trabalho como categoria marxiana fundamental, tem valor explicativo de base acerca da realidade histórica. Todavia, a categoria trabalho, compreendida como trabalho em geral (MARX, 1974), é ainda para o autor uma abstração que tem pouco sentido explicativo da realidade. É o trabalho determinado por certo modo de vida e de produção humana que estabelece o sentido para pensar o homem e sua realidade em Marx. Situado no terreno da sociedade, de algum modo,

o objeto do trabalho é pois a objetivação da vida genérica do homem, pois este não se repete de uma maneira unicamente intelectual, como acontece na consciência, mas ativamente, realmente e ele então se contempla dentro do mundo que ele criou. Logo, enquanto o trabalho alienado extorque do homem o objeto de sua produção, ele lhe rouba sua vida genérica, sua verdadeira objetividade genérica e transforma a vantagem que tem o homem sobre o animal na desvantagem de ser roubado por seu corpo não orgânico, a natureza. Do mesmo modo, degradando ao nível de instrumento a atividade própria, a livre atividade, o trabalho alienado faz da vida genérica do homem o 
instrumento de sua existência física. A consciência que tem o homem de seu gênero transforma-se, então, de tal maneira, com a alienação, que a vida genérica torna-se par ele um meio (MARX, 1989, p. 158).

No sistema capitalista, contudo, o trabalho historicamente determinado esconde sob um dissimulado aspecto de realização da força humana, o fenômeno do trabalho alienado, cujos princípios fragmentadores da consciência internalizam no sujeito o sentimento de exterioridade da sua própria ação, de expropriação da sua força produtiva, e de esvaziamento da sua inteligência criadora. Por conseguinte, Marx (1989) esclarece que, do interior da relação homem e trabalho alienado, cria-se o movimento de forças contrárias no qual, quanto mais o homem produz, menos valor ele agrega a si próprio: "Quanto menos és, quanto menos exteriorizas tua vida, tanto mais tens, tanto maior é a tua vida alienada e tanto mais armazenas da tua essência alienada" (MARX, 1974, p. 24).

Para Marx (1989), são várias as determinações que estabelecem certo sistema de alienação, além da propriedade privada, há ainda a divisão do trabalho, a conversão das relações sociais e de produção em mercadoria, a valorização do sistema do dinheiro, dentre outros que corroboram para a afirmação dessa forma social do trabalho. O trabalho alienado altera de modo cabal a elaboração histórica da consciência, privando o sujeito, em alguma medida, de sua condição de ser integral, livre e pensante.

O ser integral do homem, na amplitude constitutiva de sua vida psicofísica e de sua objetivação é compreendido por Marx (1989) como o ser genérico do homem, cuja consciência é capaz de determinar-se "perante a si próprio como espécie presente, viva, como ser universal, e portanto livre" (MARX, 1989, p. 165). Dessa forma, o homem na condição de ser genérico contrapõe-se ao homem da ordem do trabalho alienado, este último, exposto à condição de estranhamento de si mesmo como indivíduo e espécie, por fim, vê-se reduzido em sua humanidade e limitado em sua autonomia, é tolhido em sua própria capacidade de pensar e agir enquanto consciência histórica. 
Conceber a alienação como uma forma moderna do trabalho, ou ainda, como uma forma capitalista de elaboração da consciência, consiste em distinguir que o homem não se reconhece no produto de seu trabalho. Na relação de estranheza entre consciência e trabalho, o sujeito tem noções fragmentadas acerca do objeto que produz, não o compreende senão como um meio para sobreviver. Em consequência, o trabalho enquanto elaboração da consciência esvazia-se de sentido para o homem, desde esse ponto, reconhece-se uma fragmentação entre a atividade do trabalho e o pensamento, uma fragmentação que não é ontológica, mas sim dada pela forma social do trabalho. Nesse sentido, a consciência alienada está para o capital, como o trabalho está para a consciência. O poeta português Fernando Pessoa (1969, p. 73-74) expressa de algum modo o alcance da cultura do capital:

Ah, poder exprimir-me todo como um motor se exprime!

Ser completo como uma máquina!

Poder ir na vida triunfante como um automóvel último-modelo!

Poder ao menos penetrar-me fisicamente de tudo isto,

Rasgar-me todo, abrir-me completamente, tornar-me passento

A todos os perfumes de óleos e calores e carvões

Desta flora estupenda, negra, artificial e insaciável!

Nesse universo de divisão psíquica e de estranhamento de si em que o sujeito não reconhece sua humanidade nem mesmo nos produtos do seu trabalho, torna-se difícil afirmar que o homem determina seu trabalho, via de regra, é paradoxalmente definido e tutelado por este; tal encaminhamento exprime uma inversão na qual a elaboração da atividade lógica do homem deixa de ser um fim em si mesmo, transmutando-se em meio ordinário para os fins do capital. É nesse sentido que Marx (1974) explicita, acerca da permanente construção da sociedade, que

o homem retorna à caverna, etc., mas de uma forma alienada, hostil. O selvagem em sua caverna - este elemento natural que se oferece 
espontaneamente para o seu gozo e proteção - não se sente estranho, ou, melhor dito, se sente tão à vontade como um peixe na água. Mas o quarto de porão do pobre é uma habitação hostil, que "retém uma potência estranha, que só se entrega a ele quando ele entregar a ela seu suor e seu sangue", habitação que ele não pode considerar como lar - onde, finalmente, pudesse dizer: aqui estou em casa - onde ele se encontra muito mais em uma casa estranha, na casa de outro que o espreita diariamente e que o expulsa se não pagar o aluguel. Igualmente, do ponto de vista da qualidade, vê sua casa como o posto à habitação humana situada no além, no céu da riqueza (MARX, 1974, p. 28).

O autor desmistifica as determinações que convertem o homem concreto, em um meio inócuo a serviço dos fins da propriedade e do capital, desvela a destinação que embrutece as disposições humanas essenciais, sobretudo, as da razão, da ética e do conhecimento. Desse ponto de vista, a questão do conhecimento não pode ser compreendida senão com base nas contradições da vida material e dos conflitos existentes nas relações de produção. Para Marx (1974), não há uma discussão abstrata relativa ao modo de produção da vida social, sua epistemologia está referida às condições concretas da sociedade capitalista como a mais desenvolvida e antagônica forma social do trabalho. Ultrapassando os limites do seu tempo, o pensamento de Marx se constitui em uma práxis compreensiva da realidade, remete aos deslocamentos concretos da consciência histórica, cuja manifestação presente tem relação orgânica com as marcas sociais, culturais e racionais da realidade objetiva .

Marx e Engels são materialistas justamente porque se afirmam sobre as bases da categoria histórica, com base na qual não cabe "explicar a práxis a partir da ideia, mas explicar as formas ideológicas a partir da práxis material" (MARX; ENGELS, 1984, p. 58). Tributário do pensamento marxiano, Antonio Gramsci (1999; 2000; 2001) reafirma tais compreensões da realidade, suas determinações e sua forma materialista, por conseguinte, postula que toda realidade, mesmo a aparentemente mais natural é, em verdade, histórica. Para o autor italiano, o pensamento não 
é inato, mas é fruto de uma conquista social, precisa trilhar caminhos formativos que ultrapassem o senso comum, tanto quanto se subtrair as especulações abstratas e a erudição.

\section{Racionalização e fragmentação da atividade objetiva}

A problemática da articulação entre pensamento e ação na atividade objetiva humana torna-se especialmente importante quando se deseja afirmar uma visão de mundo e de formação que seja provocadora, capaz, por sua vez, de ascender a reflexão dos processos históricos. Gramsci (1999) contesta pensamentos conservadores que se tornaram referencias importantes no contexto da República italiana como os de Antonio Labriola e Gentile, que concebem a educação e o conhecimento de modo anacrônico, justamente por sustentar uma "renúncia tendenciosa a educar o povo" (GRAMSCI, 1999, p. 86).

Especialmente após a implantação do modelo industrial fordista, tornou-se difícil avançar na problemática da formação humana no contexto da racionalização, da mecanização do trabalho, sem tocar nos desdobramentos e perdas que esses processos geraram na elaboração da vida e da subjetividade das pessoas, tanto quanto, na reflexão da história. O novo tipo de esforço psíquico afirmado pelo padrão taylorista e fordista distancia-se, sobremaneira, do pensamento crítico, da autonomia, da política, assim como se aproxima do fazer, da habilidade e de um tipo de democratização que nega a formação humanista e dialética.

A problemática passa também pelas consequências da fragmentação entre o planejamento da produção e sua execução, condição esta, a que o capitalismo obrigou os processos do trabalho. Tal fragmentação foi verticalizada com o modelo produtivo fordista, tornando-se cada vez mais legítima, especialmente na dimensão da formação profissional, revelando, com isso, a atualidade inegável da obra de Gramsci, assim como as contradições clássicas desse processo ligadas à questão de que, 
do ponto de vista ontológico, pensar e fazer são duas ações diferentes que, contudo, compõem um só processo dialético.

Em Americanismo e fordismo, Gramsci (2001) discute "a separação que o taylorismo determinaria entre o trabalhador manual e o 'conteúdo humano’ do trabalho” (GRAMSCI, 2001, p. 271). O autor encaminha a discussão apresentando os problemas da racionalização e da exigência de um novo tipo de esforço físico e psíquico dos trabalhadores nos Estados Unidos da América (EUA), essa nação, por sua vez, tornou-se o modelo econômico mais avançado sob os auspícios da indústria fordista e das suas condições históricas socioculturais próprias. Desde o período anterior à Primeira Guerra Mundial, o EUA “já era uma grande economia industrial, o grande pioneiro, modelo e força propulsora da produção em massa e da cultura de massa que conquistaram o globo" (HOBSBAWN, 1995, p. 24).

Levando em consideração a reforma intelectual e moral geradas pelos movimentos econômicos do capitalismo, Gramsci (2001) explicita que o EUA com seu papel inexorável na acelerada racionalização da produção e do acumulo de capital, assumiu a dianteira como modelo de Estado liberal; posição que decorreu de suas características históricas ligadas à uma vocação laboriosa, presente também nas classes dirigentes, e ainda por sua capacidade de racionalizar a cultura e a moral na direção de um novo tipo de trabalhador e de sociedade, comprometidos em alto grau com o desenvolvimento industrial fordista.

Todavia, Gramsci (2001) faz objeção quanto à compreensão de que o modelo americano tenha sido o principal fator de impulsão das nações europeias do início do século XX ao mudarem seus paradigmas e suas estruturas econômicas laborais e culturais extremamente conservadoras. Para o autor, a experiência norte-americana fordista não é senão a propedêutica de um movimento ligado à própria forma do trabalho e das relações de produção no desenvolvimento do sistema do capital. O desenvolvimento industrial na Europa levaria inexoravelmente as suas próprias estruturas políticas e culturais tradicionais a ruírem, em virtude das novas tendências do modelo de produção do tipo fordista. 
Estavam em questão novas necessidades que implicam a racionalização vertical do trabalho e da subjetividade humana à medida que buscam direcionar toda a energia psicofísica dos homens na atividade produtiva. Esse encaminhamento tornou-se viável no caso norte-americano, segundo Gramsci (2000), graças à condição histórica preliminar dessa nação, que combinou "habilmente a força (destruição do sindicalismo operário de base territorial) com a persuasão (altos salários, diversos benefícios sociais, habilíssima propaganda ideológica e política) e conseguindo centrar toda a vida do país na produção" (GRAMSCI, 2000, p. 247). Assim, a moralidade e a visão de mundo fordista não adentrou simplesmente, de modo exterior e mecânico, a racionalidade da sociedade norte-americana. Como lembra Gramsci (2001), essa mudança foi fundada em um tipo de inteligência que se orientaria segundo a experiência, ou, segundo uma positividade e subjetividade próprias da civilização técnica, essa consciência foi paulatinamente elaborada desde o moderno homo faber e sua disposição para a atividade laboral.

Segundo Gramsci (2001), a construção da subjetividade instituída nos moldes do americanismo não prescindiu de uma disciplina psicofísica da ordem da produção para adequar os sujeitos, da clássica ordem do trabalho profissional qualificado, para um tipo mais avançado de homem tecnológico e adaptado às novas necessidades de uma economia mais acirrada. O problema é que tal racionalização banalizou e reduziu, mais precisamente, os fundamentos da práxis ligados ao pensamento. O cérebro do operário tornou-se cada vez mais adaptado a um tipo de esforço que se restringe à memória da atividade que ele exerce, por vezes, de modo repetitivo. Em algumas profissões, segundo Gramsci (2001), a suposta separação entre a elaboração manual e a intelectual seria mais acentuada. Nos ofícios assumidos por pessoas mais intelectualizadas, também as contradições reafirmaram-se enormes, desde a implantação do taylorismo e do tipo de racionalidade técnica por ele inaugurada. Segundo o autor,

é difícil atingir o grau mais elevado de qualificação profissional, que exige do operário que "esqueça" ou não reflita sobre o conteúdo 
intelectual do texto que reproduz, para poder fixar a atenção apenas na forma caligráfica das letras, se copista; para decompor a frase em palavras "abstratas" e estas em letras-caracteres e escolher rapidamente os pedaços de chumbo nas caixas; para decompor não mais apenas as palavras singulares, mas grupos de palavras, no contexto de um discurso, agrupando-as mecanicamente em siglas estenográficas; para obter rapidez na máquina de escrever, etc. O interesse do trabalhador pelo conteúdo intelectual do texto mede-se por seus erros, ou seja, é uma deficiência profissional: sua qualificação é avaliada precisamente por seu desinteresse intelectual, isto é, por sua "mecanização" (GRAMSCI, 2001, p. 271).

Gramsci (2000) indica, no trecho citado, os detalhes da destituição do pensamento em favor da instrumentalidade. Entretanto, o desdobramento dessa adaptação não consiste para o autor, em total inapetência para a reflexão extraofício. Essa questão é depreendida na crítica às premissas tayloristas, especialmente, a que pretende considerar o operário como um gorila amestrado. Para Gramsci (2000), esse ideal de Taylor é absurdo e improvável, pois, para transformar o sujeito em um gorila amestrado, seria necessário mais que automatizar a atividade laboral, requereria um embate com questões antropológicas e historicamente construídas. De um do ponto de vista gramsciano, considerar o sujeito de acordo com Taylor, somente poderia ensaiar-se, negando totalmente ao homem sua condição ontológica de consciência histórica.

Gramsci (2001) rompe com toda compreensão que separa o ser ontológico da práxis histórica. Dito de outro modo, a inexistência do homem como gorila amestrado ocorre pela impossibilidade mesma de separação entre a atividade humana genérica constitutiva do ser pensante, da materialidade e da forma social do trabalho. Do ponto de vista dessa epistemologia dialética, trata-se de considerar, necessariamente, a constante correspondência entre a construção de uma categoria lógica, enquanto elaboração pensada da realidade, com a própria realidade histórica. A fertilidade dessa relação se atualiza tendo a historicidade das 
condições objetivas de existência, como critério de verdade do objeto de conhecimento e não o procedimento lógico isolado.

\section{Práxis e formação}

Compreende-se a práxis, nesse sentido, como síntese da atividade histórica com a atividade do pensamento, uma síntese móvel, transitória, formativa. Relativamente aos intelectuais, Gramsci (2000, p. 53) afirma que "não há atividade humana da qual se possa excluir toda intervenção intelectual, não se pode separar o homo faber do homo sapiens". Por mais estreito e domesticador que se possa considerar o racionalismo técnico, ele é parte de um desenvolvimento inexorável do intelectualismo subsequente, adequado em seus valores, ao "desenvolvimento das formas reais de vida" (GRAMSCI, 2000, p. 53). Sendo assim, contraditoriamente, o novo racionalismo tornou-se parte do modo de pensar do sujeito contemporâneo.

Nas problemáticas da racionalização, é substantivo o zelo de Gramsci (2000) para manter a tensão própria da práxis, especialmente, ao postular a importância do que ele chamou de esforço muscular nervoso, essa atividade que é pensamento. A atividade produtiva é mesmo um princípio constitutivo do homem na sociedade capitalista, todavia, cabe reestabelecer a tensão do que se poderia tomar como uma premissa de fundo do pensamento gramsciano: mesmo em sua versão adaptativa e exploradora, a atividade produtiva não elimina de modo cabal as potencialidades lógicas do sujeito, sendo a ele cabível elaborar, em algum momento, sua insatisfação de classe desencadeada por "um curso de pensamentos pouco conformistas" (GRAMSCI, 2001, p. 272).

O caráter contraditório da realidade em questão se funda na relação entre capital e trabalho, entre fazer e pensar, e também, entre pensamento crítico e racionalidade técnica. A permanente correlação entre esses contrários põe em evidência os nexos que os constitui em sua materialidade histórica. Prova disso, é a exaltada preocupação do alto escalão industrial fordista com a superestrutura e com a necessidade da criação 
de iniciativas educacionais, religiosas e sociais que pudessem engendrar uma determinada visão de mundo. O caminho encontrado para fazê-lo foi o da persuasão, do consenso, dos altos salários e também de um modelo de sociedade e de Estado que pudessem, sobremaneira, controlar a mente humana em direção à racionalização ideológica e produtiva.

Segundo Gramsci (2001), os fundamentos da nova cultura, ou de um novo modo de vida propagado sob a rubrica do americanismo, não representou uma mudança na base do sistema produtivo, pelo contrário, o modelo norte-americano não se tornou senão um equivalente mais avançado do velho industrialismo europeu. O novo paradigma de cultura e de Estado visou o desenvolvimento otimizado da superestrutura, das reações intelectuais e morais em favor de um método produtivo que, sob a bandeira da democracia e da liberdade, fez avançar extraordinariamente toda a estrutura em coerência com os interesses hegemônicos. Compreende-se, assim, o caráter presumido na lição de mobilização coletiva norte-americana, cuja história não arregimentou, na mesma medida, esforços de avanço contra-hegemônicos na reflexão a respeito dos fins do modo de vida e de racionalidade fordista.

De acordo com Gramsci (2001), as condições políticas e econômicas dos Estados Unidos da América (EUA) do início do século XX tornou-se a vanguarda para a qual tendia o modelo de sociedade e de Estado contemporâneos. Desse modelo procedeu não só uma cultura, mas também uma epistemologia afirmativa que diligenciava o definitivo rompimento com a compreensão tradicional, escolástica e abstrata do conhecimento, buscando, a seu modo, a valorização da experiência, a superação da dicotomia entre espírito e matéria, demandando, contudo, encaminhamentos liberais para esses princípios.

Dewey (2007) é uma referência indispensável nesse horizonte liberal em que a partilha mais larga possível da experiência entre os homens é importante, e não é possível senão adotando um comportamento democrático. Com vistas a esta realização, Dewey compreende que o processo social não deve restringir o sentido democrático aos limites de um regime 
político, mas, antes, é preciso conceber a democracia como um modo geral de vida que se opõe à atitudes autocráticas e impositivas. A educação nesse contexto deve ser flexível no sentido de estar necessariamente vinculada às circunstâncias, pois seu objetivo "é experimental e, portanto, cresce constantemente ao ser testado na ação" (DEWEY, 2007, p. 19).

Pode-se dizer que os valores da experiência, como Dewey (2007) os define, são importantes, ainda que insuficientes para abarcar as contradições que a práxis requer, especialmente no que diz respeito ao objetivo da educação, porquanto a educação precisa de algum modo estar ligada à experiência, mas, não pode ser apenas um espelho legitimador da sociabilidade instituída. Dewey (2007) leva em consideração que o sujeito e as circunstâncias em que ele se insere são permanentemente modificados, o problema é que essa modificação, no modo como ele a compreende, é uma atividade em certo sentido subjetiva, alheia ao caráter histórico. Nesse aspecto, Dewey (2007) desconsidera o conflito que é inerente à própria democracia. Importa para o autor que não se tenha "uma idéia abstrata de educação" (DEWEY, 2007, p. 24), mas, a concretude que ele apresenta para esta questão se concentra na compreensão de que o fim de toda atividade, torna-se ao mesmo tempo, um meio:

Cada meio é um fim temporário até ser alcançado. Todo fim se torna um meio de dar prosseguimento à atividade assim que é atingido. O fim assinala a direção futura de uma atividade em que estamos envolvidos; o meio, a direção atual (DEWEY, 2007, p. 20).

Ora, a atividade humana nesse contexto está cerceada por um estatuto instrumental, e seu sentido somente se realiza por meio da utilidade ou da experiência. Trata-se de um modo de pensar que corrobora com o modelo fordista intensificador da atividade que faz conhecer pelo controle ou pelo fabrico de toda substância física ou psíquica, abarcando também a aquisição do hábito. Assim, o conhecimento, ainda que considerado pelo 
autor americano como indissociável da prática, ganha necessariamente uma utilidade imediata.

A indissociabilidade entre o saber e ofazer aparece nas elucidações de Dewey (2007) acerca da educação como um ponto cego que, desde a Antiguidade, se exprime tão somente pela divisão de classes. Segundo Dewey (2007), a superação da dicotomia entre cultura e utilidade é uma importante conquista para a transformação da vida social, mas, "sua relevância está em tirar proveito dessas transformações para o desenvolvimento de uma sociedade verdadeiramente democrática, na qual todos compartilhem os serviços úteis e todos aproveitem a dignidade do lazer" (DEWEY, 2007, p. 39). Tais desdobramentos são possíveis quanto mais se concilie "a educação liberal com o treinamento para a utilidade social" (DEWEY, 2007, p. 44).

O próprio Dewey critica o dualismo de Durkheim, que culmina na separação entre saber e fazer, ou ainda entre teoria e prática, nesse ponto da utilidade social, mas talvez se possa dizer que Dewey se aproxima do sociólogo francês fundador da categoria de fato social, se pudermos considerar que o conceito de fato social é bastante elucidativo da compreensão de que "não há oposição entre o individual e social quando as atividades da mente partem das crenças costumeiras e se esforçam por transformá-las de maneira efetiva, ganhando assim a aceitação geral" (DEWEY, 2007, p. 56). Nessa perspectiva, Dewey (2008) segue, sutilmente, o caminho da conformação social, compartilha em certa medida do viés no qual o conhecimento e a dimensão lógica da realidade se estabelecem em face à observação, ou ainda, em face à experiência no sentido da habilidade, mantendo-se, portanto, à margem das realidades históricas, econômicas, políticas e sociais implícitas nesse contexto.

No lado oposto, Gramsci (1999) não concebe o pensamento e a lógica de elucidação da realidade como capacidade técnica, ou mesmo capacidade especulativa, desligadas da historicidade e das ciências concretas particulares. Se uma das questões fundamentais da epistemologia dialética é a apreensão do caráter histórico do sujeito e do objeto do 
conhecimento, é porque a materialidade histórica destes dois elementos não significa um sucessão cronológica de fatos consumados no percurso da civilização, trata-se, antes de tudo, do reconhecimento de que todos os aspectos da realidade concreta, mesmo os aparentemente naturais, são em verdade sociais e historicamente construídos.

Longe de ser inata, a fecundidade da capacidade lógica do homem, como esforço do pensamento crítico, ocorre no campo em que "revela-se a metodologia histórica" (GRAMSCI, 1999, p. 184). Está em questão o fato de que "uma filosofia da práxis só pode se apresentar, inicialmente, em atitude polêmica e crítica, como superação da maneira de pensar precedente e do pensamento concreto existente" (GRAMSCI, 1999, p. 101). O caráter histórico-crítico do projeto revolucionário se realiza, ao mesmo tempo, no plano dos conceitos e no plano concreto das relações de produção da vida. Nessa articulação necessária é que se afirma a questão da cultura e da hegemonia fora do círculo de compreensão elitista, antipopular ou estritamente acadêmico.

A compreensão lógica da realidade não é um processo espontâneo nem linear, em Gramsci (1999), o homem não está dotado de uma consciência teórica a priori, ainda que sua própria atividade objetiva possa ser considerada como um tipo de conhecimento da realidade. Na verdade, o plano do conhecimento põe em tensão permanente, duas dimensões inseparáveis: a consciência elaborada na atividade-pensamento do sujeito que está "implícita na sua ação" (GRAMSCI, 1999, p. 103), com outra consciência acolhida acriticamente de sua cultura e valores.

Em Apontamentos para uma introdução e um encaminhamento ao estudo da filosofia e da história da cultura (1999), Gramsci põe em questão a importância da reflexão acerca da história, da filosofia e do método no qual a práxis tem uma importância central. Distingue-se o marxismo no contexto da obra de Gramsci como filosofia da práxis, não somente, para dissuadir a violência dos censores, mas, sobretudo, para destacá-lo como pensamento e visão de mundo que se constitui criticamente na sua fecundidade lógico-histórica, distinto dos desdobramentos 
afirmativos e consensuais que foram inaugurados pelo Reprodutivismo. Para Gramsci (1999) é preciso superar a dicotomia que se faz da práxis com o senso comum, pois,

a compreensão crítica de si mesmo é obtida, portanto, através de uma luta de "hegemonias", políticas de direções contrastantes, primeiro no campo da ética, depois no da política, atingindo, finalmente, uma elaboração superior da própria concepção do real. A consciência de fazer parte de uma determinada força hegemônica (isto é, a consciência política) é a primeira fase de uma ulterior e progressiva autoconsciência, na qual teoria e prática finalmente se unificam (GRAMSCI, 1999, p. 103).

$\mathrm{Na}$ atividade objetiva há uma articulação possível com o conhecimento da realidade à medida que esta se transforma. Mas, os esforços de compreensão da realidade são construídos e determinantes na vida do grupo social,

a compreensão crítica de si mesmo é obtida, portanto, através de uma luta de "hegemonias", políticas de direções contrastantes, primeiro no campo da ética, depois no da política, atingindo, finalmente, uma elaboração superior da própria concepção do real. A consciência de fazer parte de uma determinada força hegemônica (isto é, a consciência política) é a primeira fase de uma ulterior e progressiva autoconsciência, na qual teoria e prática finalmente se unificam (GRAMSCI, 1999, p. 103).

A política é a atividade por excelência da práxis, por isso, ela assegura a relação entre senso comum e um modo de pensar crítico, e o faz, por meio dos intelectuais. Com efeito, os intelectuais orgânicos são justamente sujeitos da cultura capazes de elaborar uma compreensão dos meios de poder, como a política e a educação, sem reduzi-las a mero instrumento de reprodução do capital. Não se pode perder de vista que o sistema capitalista sustenta em si mesmo forças sociais contraditórias 
que podem levar, em alguma medida, à sua própria superação. Pois, do ponto de vista histórico, a instrumentalidade que se possa habituar a razão também é relativa, ela não é absoluta, não pode encerrar o devir, o conhecimento e a sociedade. Eric Hobsbawm oferece argumentos interessantes dessa necessidade constante de elaboração e de superação, que é inerente à formação, não somente dos intelectuais, mas da própria racionalidade humana. Para o autor,

a destruição do passado - ou melhor, dos mecanismos sociais que vinculam nossa experiência pessoal à das gerações passadas - é um dos fenômenos mais característicos e lúgubres do final do século XX. Quase todos os jovens de hoje crescem numa espécie de presente contínuo, sem qualquer relação orgânica com o passado público da época em que vivem. Por isso os historiadores, cujo o ofício é lembrar o que os outros esquecem, tornam-se mais importantes do que nunca no fim do segundo milênio. Por esse mesmo motivo, porém, eles têm de ser mais que simples cronistas, memorialistas e compiladores. Em 1989 todos os governos do mundo, e particularmente todos os ministérios do Exterior do mundo, ter-se-iam beneficiado de um seminário sobre os acordos de paz firmados após as duas guerras mundiais, que a maioria deles aparentemente havia esquecido (HOBSBAWM, 1995, p. 13).

O que se pode aprender com a epistemológica dialética é, justamente, cultivar a tensão indispensável entre os dois modos antagônicos de compreender a realidade: o cotidiano e o crítico. Cabe elevar concretamente as condições de reflexão histórica do sujeito, a formação tem contribuições a realizar quanto mais possibilite o alargamento da sua visão de mundo, afastando-se da conformação e da naturalização das contradições do modo de vida capitalista. Para Gramsci (2000), se a técnica-trabalho pode alcançar a técnica-ciência, e com ela a concepção humanista histórica da realidade, isso somente pode se constituir em oposição à realidade instituída. Na conquista de seus direitos e de sua humanidade, o homem contemporâneo a ser formado na qualidade de um sujeito crítico, ou de um sujeito da cultura, participa dos modos reais de vida e eleva-se nas possibilidades do conhecimento. 
Com base, em sua cultura e formação, atribui significados sociais, políticos, estéticos, éticos e históricos a si mesmo e à sua vida coletiva, torna-se um “dirigente (especialista + político)" (GRAMSCI, 2000, p. 53).

Sob esse ponto de vista, se a relação entre senso comum e pensamento crítico é indispensável para que o próprio pensamento mantenha a sua materialidade, é, portanto, por meio "deste contato que uma filosofia se torna histórica, depura-se dos elementos intelectualistas de natureza individual e se transforma em vida" (GRAMSCI, 1999, p. 100), segue-se que Gramsci submete a teoria à práxis, tornando-a capaz de elevar-se a uma historicização concreta do pensamento e da filosofia.

A crítica da sociedade e do pensamento avança com Gramsci (1999) em um campo instituinte, mantendo o caráter dialético, não sucumbindo à banalização indiscriminada dos processos formativos, não cedendo do ponto de vista epistemológico à cientificidade, à metafísica ingênua e ao determinismo. Levando em consideração a inseparabilidade entre estrutura e superestrutura, deve-se considerar atentamente a importância da superestrutura e seu valor ideológico num plano em que o sujeito possa elaborar seu pensamento e desmistificar as contradições das forças materiais de produção da vida social. Nesse intento, Gramsci (1999) sugere a linguagem realista e histórica que favoreça o desenvolvimento orgânico da filosofia da práxis, até transformá-la em um preceito hegemônico da cultura.

Gradualmente amadurecida na sociedade capitalista, a racionalidade instrumental torna as pessoas cada vez mais adaptadas ao desprezo pelo pensamento. A problemática do pensamento no contexto da práxis abarca o reconhecimento de que as condições lógico-históricas do conhecimento são mutáveis, não constituindo verdades eternas, sendo o valor puramente instrumental da lógica da rubrica da erudição, tendo como fim, o seu próprio conteúdo abstrato. O conhecimento dialético da sociedade e da sua realidade não se sustenta pela ótica da lógica formal, assim como, não se sustenta pela formação que não prioriza a capacidade de reflexão. Isso se dá pela razão mesma de que quaisquer esquematismos genéricos anulam "o problema da vida e da ação moral, 
da formação da personalidade e da consciência, o que nós costumamos chamar de historicidade do espírito, que é corolário de filosofia abstrata" (GRAMSCI, 1999, p. 181).

Permanece o desafio de conceber a questão da formação na sociedade e da educação que tendem a considerar o pensamento como um discurso exterior, à margem da atividade humana objetiva. Cabe refletir que assim como a práxis não se realiza fora da história, ela também não se concretiza integralmente fora dos conceitos. Por isso é importante cultivar na formação o universo da imaginação, das teorias, e do pensamento concretamente situado. Isso pede esforços bem embasados e críticos da cultura escolar e do trabalho docente. E, não prescindir da tensão entre a realidade histórica e sua compreensão lógica é uma emergência da formação atual, pois quase sempre está à espreita, como esclarece Adorno (1995), "o espírito burguês [que] reúne a autonomia e a aversão pragmatista pela teoria tão antinomicamente quanto a sociedade que o sustenta" (ADORNO, 1995, p. 204, grifo meu).

Se ação e pensamento são faces de uma mesma realidade, o distanciamento entre essas duas dimensões torna-se fragmentação do ser do homem, revela-se como esvaziamento de sua condição racional, exprime, antes de tudo, o "instrumentalismo burguês, que fetichiza os meios porque a reflexão sobre os fins se torna intolerável para o tipo de práxis que lhe é próprio" (ADORNO, 1995, p. 217). Triunfa, desse modo a heteronomia como um modo de vida, logo, um modo de produção da vida alienado que abdica de modo presumido das possibilidades do pensamento. Outrossim, a atividade lógico-histórica subsiste ontologicamente no homem e, dentro de condições históricas a saber, manifesta em algum momento sua materialidade lógica, estética, científica e política. Resistir às condições concretas da sociedade capitalista, por mais paradoxal que pareça, é erigir esforços de cultura e de formação humana que não afaste o que a história juntou. 


\section{Referências}

ADORNO, Theodor W. Notas marginais sobre teoria e práxis. In: . Palavras e sinais: modelos críticos 2. Rio de Janeiro: Vozes, 1995. p. 202-229.

DEWEY, John. Democracia e educação: capítulos essenciais, São Paulo: Ática, 2007.

GRAMSCI. Antonio. Americanismo e fordismo. In: . Cadernos do cárcere. v. 4. Tradução de Carlos Nelson Coutinho, Rio de Janeiro: Civilização Brasileira, 2001. p. 235-282.

. Introdução ao estudo da filosofia. In: . Cadernos do cárcere. v. 1. Tradução de Carlos Nelson Coutinho, Rio de Janeiro: Civilização Brasileira, 1999. p. 81-226.

. Os intelectuais. O princípio educativo. In: . Cadernos do cárcere. v. 2. Tradução de Carlos Nelson Coutinho, Rio de Janeiro: Civilização Brasileira, 2000. p. 11-53.

HOBSBAWM, Eric. Era dos extremos: o breve século XX. São Paulo: Companhia das Letras, 1995.

MARX, Karl; ENGELS, Friedrich. A ideologia alemã: teses sobre Feuerbach. São Paulo: Moraes, 1984.

. Manuscritos econômicos-filosóficos: primeiro e segundo manuscritos. Lisboa: Edições 70, 1989.

. Manuscritos econômicos-filosóficos: terceiro manuscrito. São Paulo: Abril Cultural, 1974.

PESSOA, Fernando. Ode triunfal. In: Janeiro: Aguilar, 1969. p. 73-79. . Obra poética. Rio de

Data de registro: 22/07/2014

Data de aceite: 14/11/2015 